\title{
Educación Jesuita
}

\section{Una tradición viva en el siglo 21}

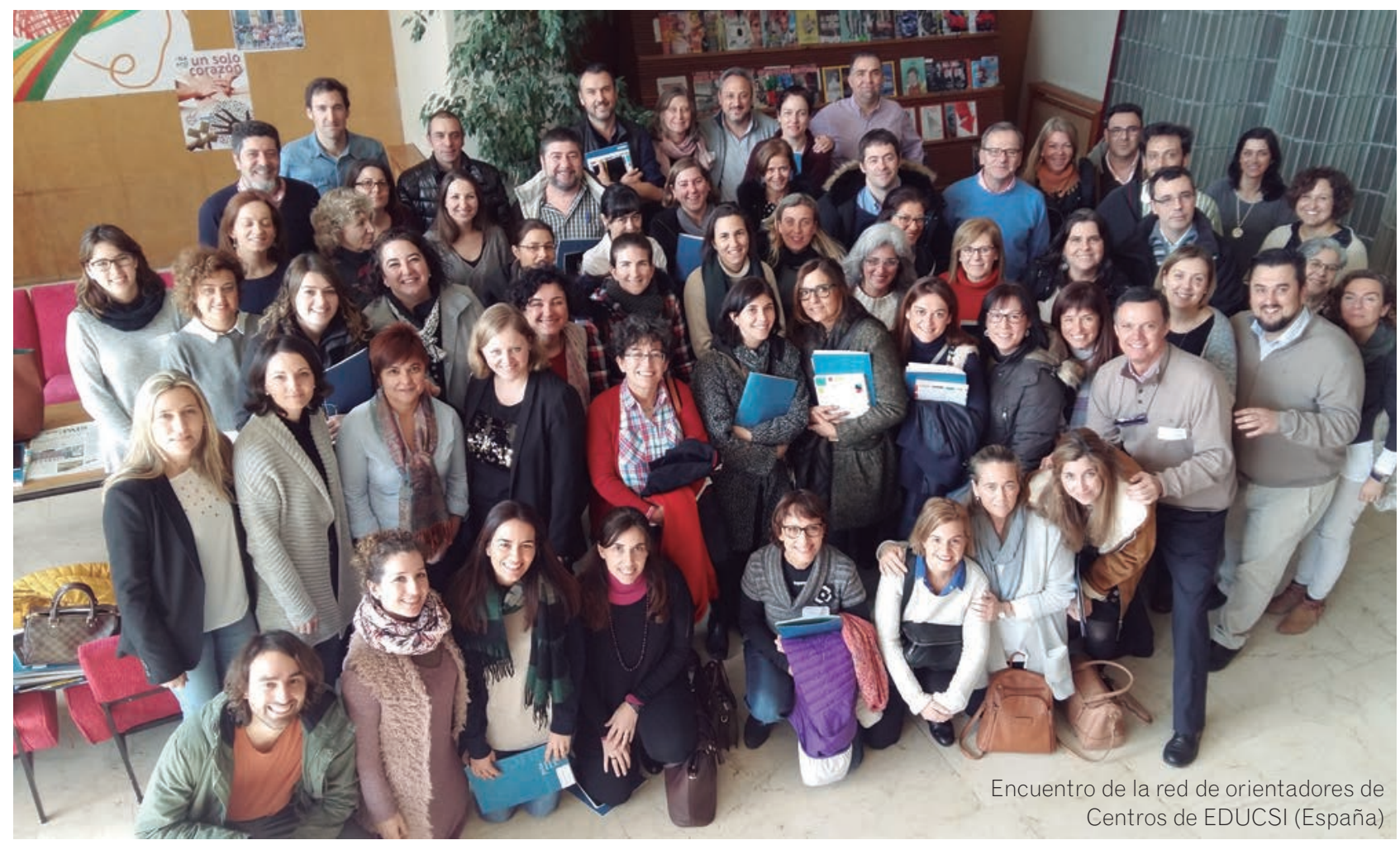

Los primeros jesuitas soñaban una Compañía de Jesús ligera, entregada totalmente al servicio de Dios a través de la Iglesia y se veían como misioneros itinerantes que iban de un lugar a otro predicando, enseñando el catecismo y viviendo de limosnas. En este artículo se hace un recorrido por los diferentes documentos que han ido guiando el

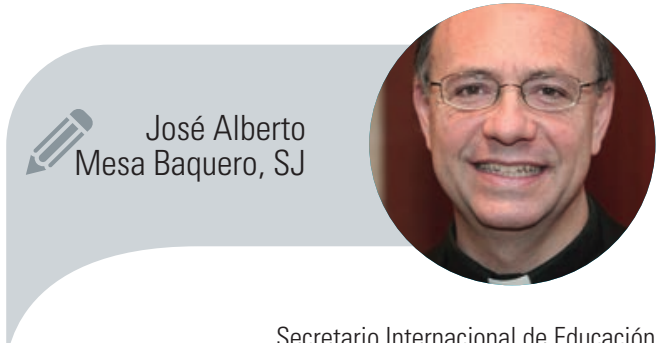

Secretario Internacional de Educación de la Compañía de Jesús (Roma) jesedu-dir@sjcuria.org https://www.educatemagis.org/printable-map/ camino desde entonces y que conforman la tradición educativa de la Compañía hasta llegar al texto que nos ocupa "Una tradición viva", con el que se pretende seguir avanzando, con fidelidad creativa, en las respuestas a los retos que nos plantea una educación global y de oportunidades para todos.

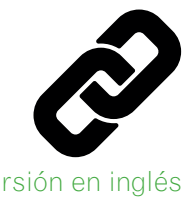



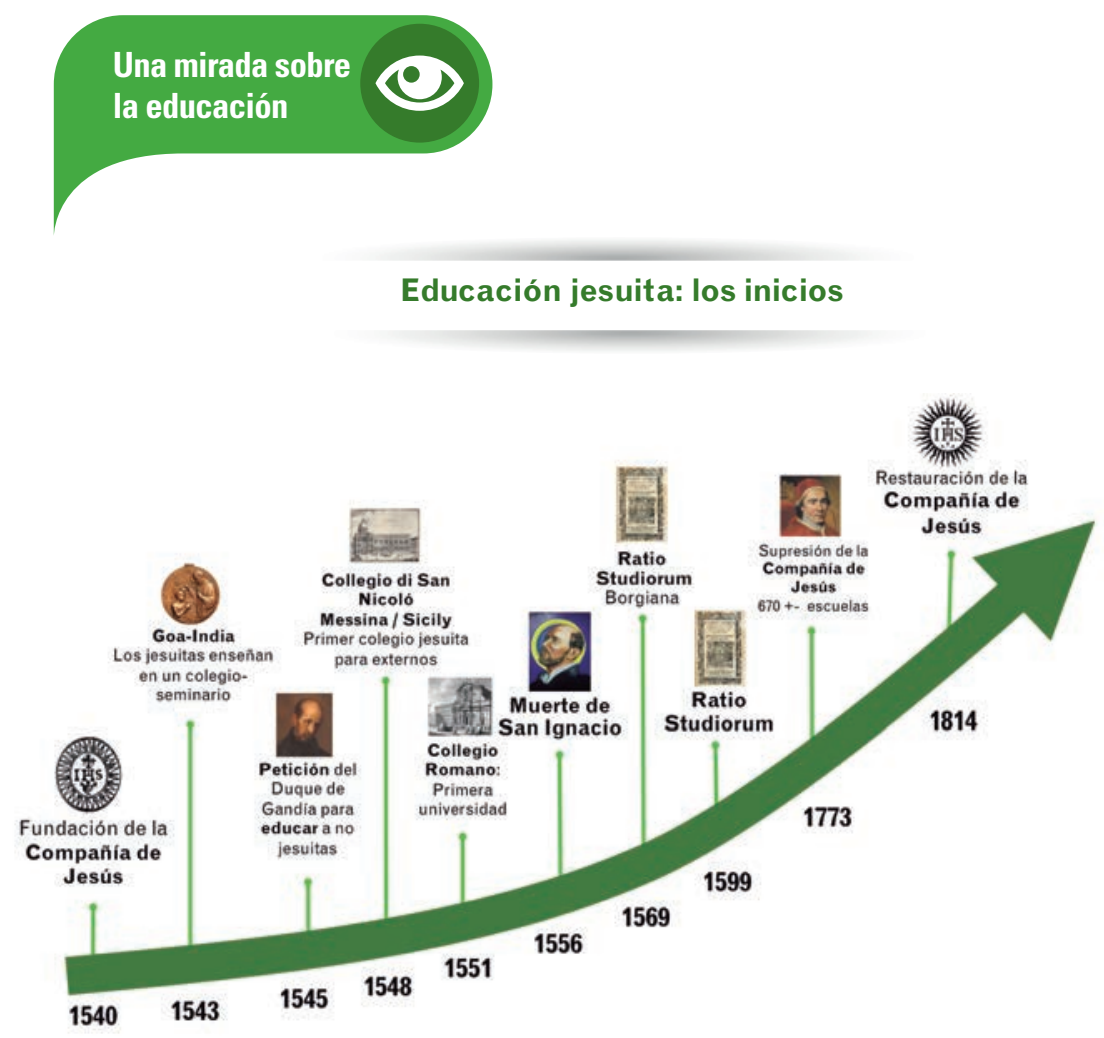

era sin embargo muy lógico. Los jesuitas descubrieron en la educación un poderoso ministerio que les permitía responder a su motivación inicial de llevar a otros a Dios compartiendo su experiencia espiritual y ayudándolos a progresar en la vida (Constituciones $n .{ }^{\circ} 2$ ).

Pero, aun teniendo claro que la educación era un campo apostólico privilegiado, los primeros jesuitas entendieron que tenían que aprender y prepararse para ser maestros. Por ello, usando una imagen actual, se fueron al supermercado educativo de la época y escogieron aquellos ingredientes pedagógicos que les parecie-

Los primeros jesuitas soñaban una Compañía de Jesús ligera, entregada totalmente al servicio de Dios a través de la Iglesia y se veían como misioneros itinerantes que iban de un lugar a otro predicando, enseñando el catecismo y viviendo de limosnas. Sin embargo, como suele pasar, Dios tenía otros planes... Ignacio de Loyola comenzó a recibir peticiones de muchas partes del mundo para que la formación que estaba ofreciendo a aquellos que querían unirse a la Compañía fuera compartida con los no jesuitas. El Duque de Gandía, Francisco de Borja, le solicitaba que abriera un colegio en sus territorios donde también se pudieran educar otros. Finalmente, esto ocurrió en 1545 con gran acogida de muchas familias que querían ver a sus hijos beneficiarse de la educación de los jesuitas. Ya Francisco Javier había solicitado unos años antes (1542) que Ignacio mandara jesuitas para trabajar en un colegio-seminario diocesano en Goa, India. En 1548 finalmente Ignacio tomó una decisión que cambió el curso de la historia de la Compañía como respuesta a la solicitud insistente de los líderes de Mesina en Sicilia: se abrió el primer colegio destinado principalmente a no jesuitas. Los que soñaban ser peregrinos ahora se convierten, en gran parte, en maestros de escuelas interesados en la pedagogía, el currículo, la consecución de fondos y el mantenimiento de instituciones para la enseñanza gratuita.

Para los primeros jesuitas este cambio, inesperado y hasta cierto punto paradójico,

ron más pertinentes para lograr una educación de calidad en consonancia con su experiencia espiritual. De la Universidad de París asumieron su método ordenado y secuencial; de los humanistas italianos aprendieron que el fin de una institución educativa debe ser la preparación para una vida al servicio del bien común y por ello la educación se debe orientar a la formación de un sólido carácter moral de la persona. De estos mismos humanistas adoptaron el currículo que proponían. De su propia experiencia espiritual aportaron una visión de lo que significa una vida plena en relación con Dios y en el servicio a los demás (La pedagogía ignaciana, Mensajero-Sal Terrae-Universidad Pontificia Comillas, Barcelona, 2019).

Los primeros jesuitas debieron, pues, aprender haciendo. Cuando aceptaron abrir el Collegio de San Nicolò en Mesina no tenían todavía claramente definido lo que querían hacer. Es más, solo hasta 1599, es decir más de 50 años después de trabajar en educación, el P. General Acquaviva promulgó la Ratio Studiorum; el primer documento oficial sobre educación que orientó los colegios. La Ratio Studiorum definía el currículo, la pedagogía y la estructura de una escuela jesuita. En este sentido los primeros jesuitas adoptaron una metodología pragmática para su aventura educativa de ir aprendiendo a medida que iban haciendo. Esta visión pragmática se hallaba ya en las constituciones escritas por Ignacio, insistiendo en que las normas y decisiones deberían 


\section{Una tradición viva: el camino contemporáneo para la renovación y la colaboración}

adaptarse y aplicarse según "tiempos, lugares y personas".

La Ratio Studiorum orientó la educación de la Compañía hasta 1906 cuando se juzga que no se puede continuar con ella pues los nuevos tiempos no lo permitían (Congregación General 25, D. 12). Allí se comienza un nuevo largo proceso de discernimiento que Ilevará a que en 1986 se publique un nuevo documento Características de la educación de la Compañía de Jesús ${ }^{1}$ que propone 28 rasgos distintivos de la educación jesuita y que logra crear un sentido de unidad en medio de la diversidad de sistemas educativos nacionales y regionales en los que los colegios jesuitas operan en este momento. Pocos años más tarde, en 1993, se publica otro documento, Pedagogía ignaciana: un planteamiento práctico $^{2}$ (conocido popularmente como el PPI - Paradigma pedagógico ignaciano) con el fin de presentar los elementos esenciales del estilo pedagógico que orientan la práctica de la enseñanza-aprendizaje en el aula a través de 5 dimensiones interconectadas: (1) entender el contexto del estudiante para poder propiciar una (2) experiencia significativa que se profundiza a través de la (3) reflexión y que se expresa a través de una (4) acción que transforma al educando y que se (5) evalúa para conocer sus efectos y alimentar el proceso. Estos dos documentos han conformado el marco contemporáneo referencial de la educación de la Compañía.

Sin embargo, la Compañía de Jesús es consciente de que vivimos en una época de rápidos cambios a todos los niveles -incluyendo el educativo-y que, en respuesta a ello, nuestros colegios también deben mantener una reflexión y discernimiento constante para reconocer los retos y oportunidades que este cambio vertiginoso conIleva. Por ello, después de más de 8 años de discusiones y trabajo, la ICAJE (Comisión Internacional del Apostolado Educativo de la Compañía de Jesús) presenta un nuevo

1 http://www.sjweb.info/documents/education/ characteristics_sp.pdf

2 http://www.sjweb.info/documents/education/ pedagogy_sp.pdf

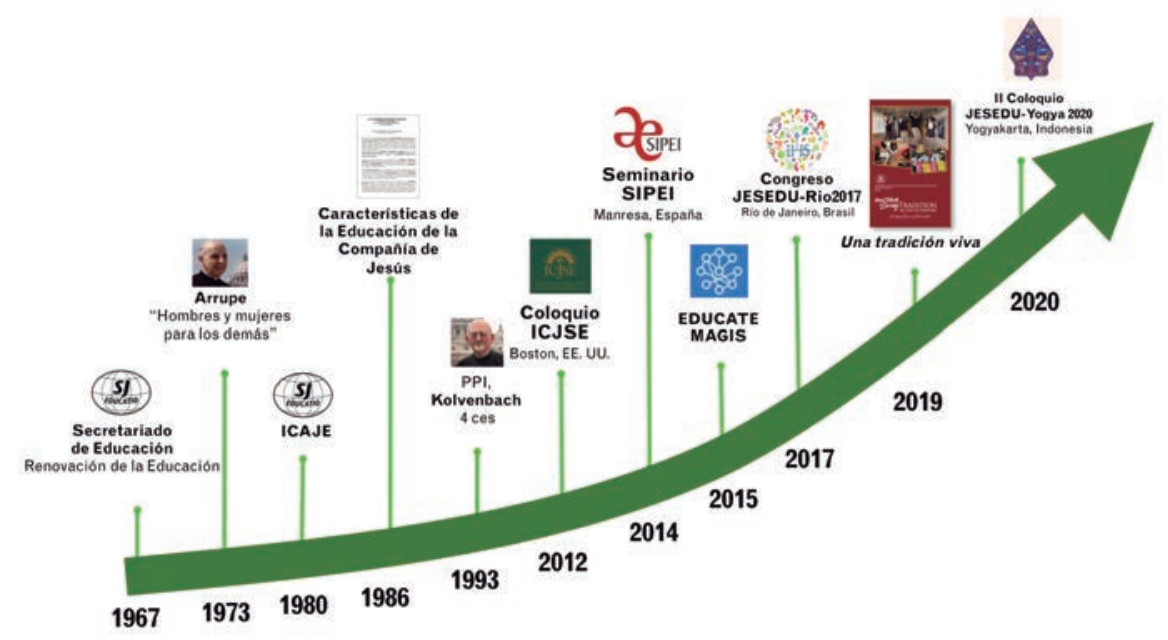

documento Colegios jesuitas: una tradición viva en el siglo 21 - Un ejercicio continuo de discernimiento, abreviado: Una tradición viva.

Este nuevo documento se desarrolla en tres partes interrelacionadas. En una primera el documento se sitúa dentro del contexto de los documentos fundacionales que ya hemos nombrado anteriormente como el de Características de 1986 y el PPI de 1993. En este sentido como el P. General Arturo Sosa SJ afirma en su carta de promulgación: Una tradición viva "debe ser visto como parte del proceso de discernimiento que nuestro apostolado educativo ha mantenido desde que se publicaron por primera vez las Características y el Paradigma pedagógico ignaciano". Así, "Una tradición viva no sustituye los documentos anteriores, sino que los complementa y actualiza como un ejercicio continuo de discernimiento. Los tres deben tomarse juntos como el marco contemporáneo de la educación jesuita". En esta primera parte también se enmarca el documento dentro de las preferencias apostólicas universales ${ }^{3}$ de la Compañía de Jesús que el P. General anuncia a comienzos del año 2019 y que guiarán los esfuerzos apostólicos de la Compañía en los próximos 10 años.

3 https://jesuits.global/es/documentos/send/8-uapdocs/62-preferencias-apostolicas-universales 


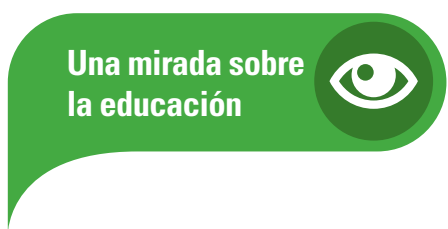

\section{Dimensiones del paradigma pedagógico ignaciano}

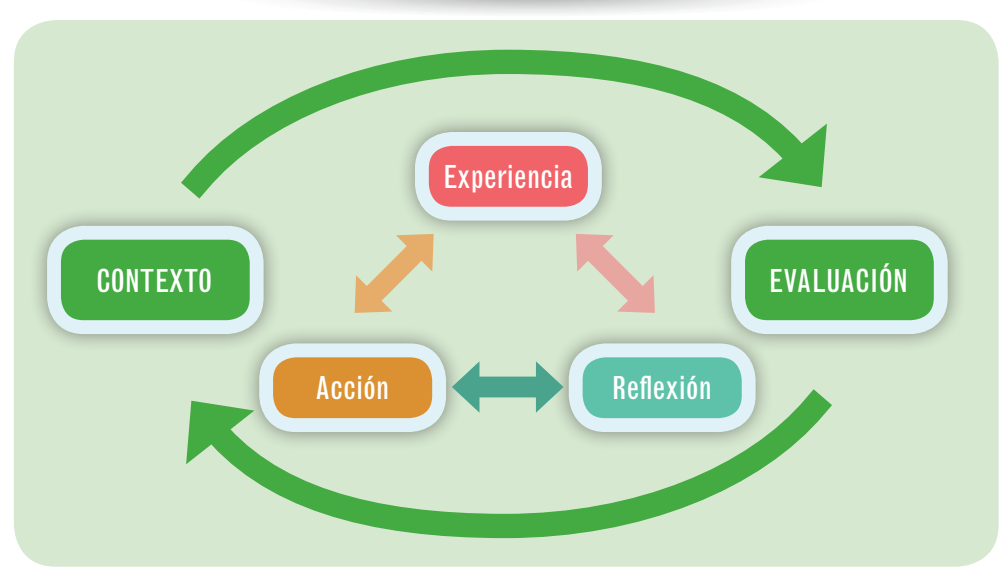

Estas preferencias se constituyen en orientaciones que definen nuestro estilo de trabajar y concebir la misión de la Compañía como servicio a la fe, a la justicia y a la reconciliación. Estas preferencias deben inspirar nuestros colegios para que su labor y su propuesta pedagógica se oriente desde ellas. Así, todas nuestras obras educativas deben incluir en sus procesos de discernimiento y planeamiento la manera en la que estas preferencias orientan su labor, y responder a ellas con creatividad y compromiso en todo lo que hacen. El papa Francisco ha confirmado estas preferencias como expresión de lo que la Iglesia espera de la Compañía en los próximos años. Al mismo tiempo ha señalado: "La primera preferencia es capital porque supone como condición de base el trato del jesuita con el Señor, la vida personal y comunitaria de oración y discernimiento... sin esta actitud orante lo otro no funciona" (Carta del papa Francisco, 6 de febrero de 2019).

Finalmente, en esta primera parte se presentan otros dos documentos más recientes que hacen parte del contexto actual (1) La Educación Jesuita apunta a la excelencia humana (2015) que define esta excelencia en términos de educar hombres y mujeres dentro de las 4 ces: consciencia, competencia, compasión y compromiso. Estas 4 ces expresan los elementos fundamentales de la excelencia humana que se busca en los colegios de la Compañía. (2) Los acuerdos finales del Congreso de delegados de educación JESEDU-Rio (2017) en que presenta la agenda global para que nuestros colegios puedan "actuar como un cuerpo universal con una misión universal (CG35, D.2. No. 20)". Allí se presentan los compromisos que permiten lograrlo en la forma de 13 acciones que deben ser implementadas en los colegios y redes educativas.

Vale anotar que la afinidad entre los acuerdos finales del JESEDU-Rio y las Preferencias Apostólicas Universales es notable. Los dos comparten una misma perspectiva y temas comunes... esta coincidencia solo se puede explicar porque jes el mismo Espíritu Santo trabajando!

La segunda parte de Una tradición viva ${ }^{4}$ se dedica a reflexionar sobre algunos de los aspectos más importantes de la realidad global. Esto se hace a nivel de la realidad sociopolítica, la educación, la práctica religiosa, la Iglesia católica y la Compañía de Jesús. Se reconoce que hay muchos elementos nuevos en la realidad desde la publicación de los documentos Características y PPI. Además, como advierte el documento: "Cuando reflexionamos sobre el pasado, es importante honrar el principio fundamental de la educación jesuita, reflejado en la Pedagogía ignaciana, de que el aprendizaje empieza por una cuidadosa reflexión sobre el contexto" (n. $\left.{ }^{\circ} 61\right)$. En este sentido, siempre ha sido parte del modo de proceder jesuita el prestar atención al contexto en el que se desenvuelve el aprendizaje y discernir las oportunidades y retos que se nos presentan. El P. General Sosa lo expresó bien en su discurso durante el Congreso JESEDU-Rio:

"Esta necesidad de comprender a fondo nuestro mundo para poder ofrecer el mayor y el mejor servicio a la Gloria de Dios es la razón por la cual entendemos nuestra misión como apostolado intelectual. Nuestro deseo es entender el ser humano y el mundo, en su complejidad, para que el ser humano pueda configurar el mundo de un modo más compasivo y por tanto más divino" (n. ${ }^{\circ} 21$ ).

En este mismo discurso advertía que "es necesario que nuestras instituciones

4 https://3eh4ot43gk9g3h1uu7edbbf1-wpengine. netdna-ssl.com/wp-content/uploads/documents/2019/11/Documento-Una-Tradcio\%CC\%81nViva-ES-F-alta-resolucion.pdf 
sean conscientes del cambio antropológico y cultural que estamos presenciando y sepan educar y formar de un modo nuevo para un futuro distinto" ( $\left.n .^{\circ} 49\right)$.

Esta segunda parte de Una tradición viva quiere invitar a los educadores y comunidades educativas a acercarnos a la realidad de nuestros contextos, entenderlos mejor, y así renovar nuestra propuesta educativa para que pueda ser una respuesta relevante ante estos nuevos contextos.

En la tercera parte del documento se presentan 10 identificadores globales de los colegios jesuitas: "Vemos estos identificadores como compromisos que cada colegio jesuita debe asumir. Son extraídos de recursos como Las características de la educación jesuita y Las preferencias apostólicas universales tal como afrontan la realidad actual del mundo" ( $\left.n .{ }^{\circ} 157\right)$.

Los 10 identificadores describen el deber ser de un colegio jesuita en sus características más importantes:

1. Católico, empeñado en una formación profunda en la fe en diálogo con otras religiones y visiones del mundo.

2. Comprometido en crear un ambiente escolar seguro y saludable para todos.

3. Comprometido con la ciudadanía global.

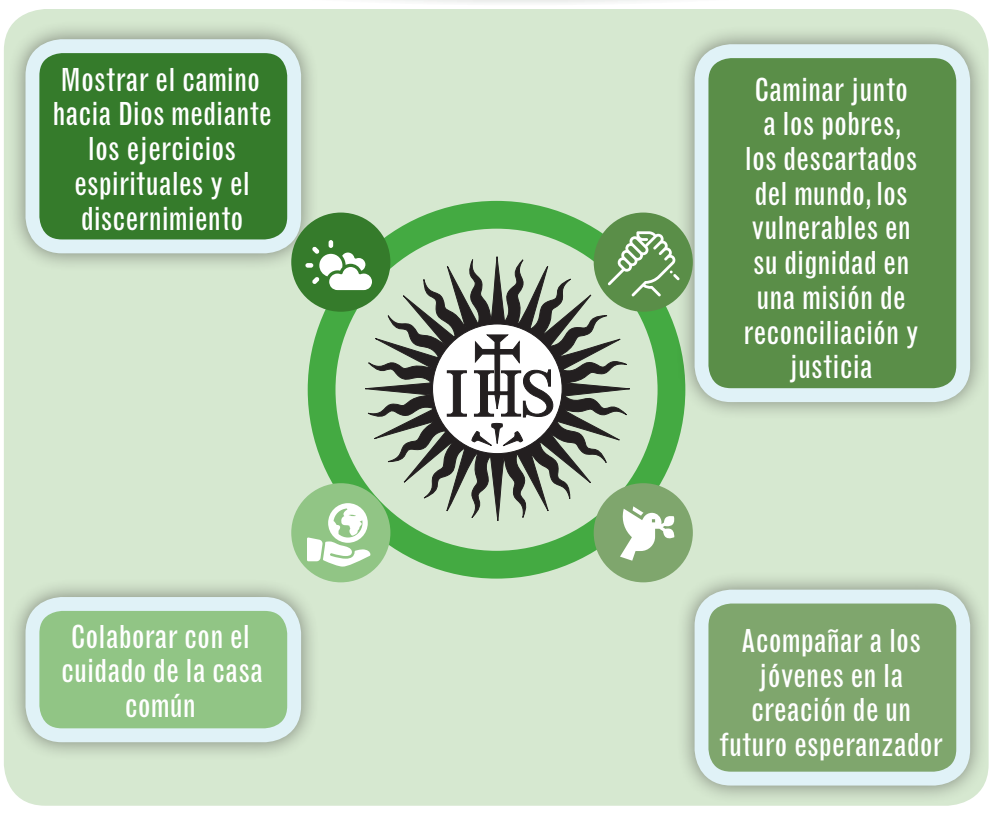

4. Comprometido con el cuidado de toda la creación.

5. Comprometido con la justicia.

6. Comprometido a ser accesible para todos.

7. Comprometido con la interculturalidad.

8. Comprometido en ser una red global al servicio de la misión.

9. Comprometido con la excelencia humana.

10. Comprometido con el aprendizaje a lo largo de la vida.

Estos identificadores buscan ayudar a los colegios a mantener su identidad

\section{MÁSTER EN}

\section{PEDAGOGIAA IGNACIANA}

\section{¿PARA QUIÉN?}

Dirigido a docentes de la Compañía de Jesús, responsables de educación y profesorado de instituciones que comparten la inspiración ignaciana.

METODOLOGIA SEMIPRESENCIAL

Actividad permanente del alumnado y acompañamiento de profesor/a-tutor/a.

Sesiones presenciales en Madrid, Loyola y Manresa.

\section{IDENTIDAD IGNACIANA}

Un máster interdisciplinar de carácter práctico que responde a los retos actuales de la Educación, aunando la innovación y la sabiduría que ofrece la tradición educativa jesuita.

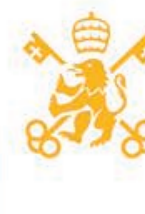

\section{COMILLAS} UNIVERSIDAD PONTIFICIA

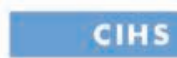
jo

\section{nto} >

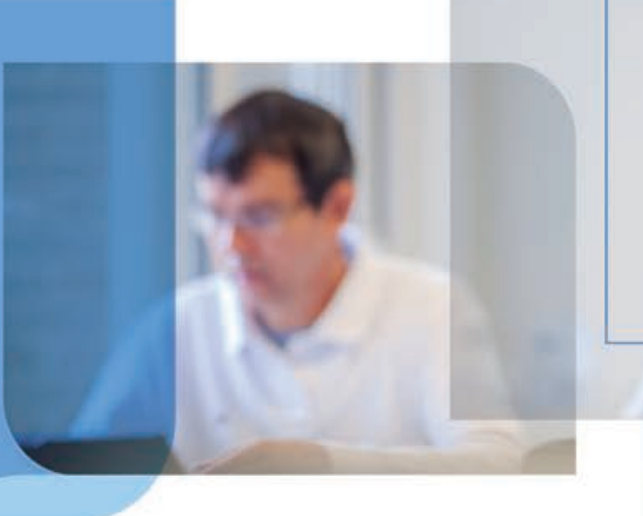

LA UNIVERSIDAD JESUITA DE MADRID

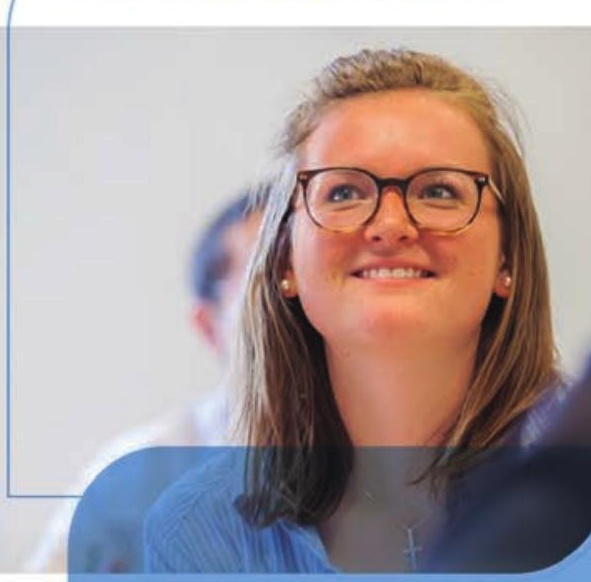

CONTACTAR:

pedagogia.ignaciana@deusto.es 
apostólica y, al mismo tiempo, que permanezcan centrados en la misión para la cual han sido fundados desde sus orígenes en tiempos de Ignacio de Loyola: para la gloria de Dios y el bien de las personas, - como la Compañía lo ha definido en tiempos modernos para el servicio de la fe, la justicia y la reconciliación.

Cada identificador se explica brevemente y luego, al igual que cada sección a lo largo del libro, va acompañado de unas preguntas que buscan ayudar a los educadores en el discernimiento de cómo entenderlo y cómo responder a este identificador. Las preguntas pretenden estimular la conversación entre los diferentes actores de la eduación jesuita para que la tradición continue viva. Así, como lo expresa el P. General en su carta de anuncio al documento, este "sigue esta tradición de ayudar a nuestro apostolado educativo a reflejar y discernir los desafíos y oportunidades particulares de nuestro tiempo, continuando el proceso necesario de renovación, innovación y re-imaginación, que nuestra educación requiere durante este cambio de época que experimentamos hoy". Es aquí donde el nombre del nuevo documento revela toda su fuerza. La tradición educativa de la Compañía es una tradición viva que impulsa a los colegios a una actitud de apertura hacia el presente y el futuro, que debe superar la tentación de una mirada complaciente hacia el pasado y de entender la tradición solo como reproducción de lo que ya se

\section{(DA) DARA SABER MÂS}

Mesa, J. A. (2019). La pedagogía ignaciana. Textos clásicos y contemporáneos sobre la educación de la Compañía de Jesús desde san Ignacio de Loyola hasta nuestros días. Madrid: Mensajero-Sal Terrae-Universidad Pontificia Comillas.

GIL CoriA, E. (1999). La pedagogía de los jesuitas, ayer y hoy. Madrid: Universidad Pontificia Comillas.

Pizarro Llorente, H. (2019). La pedagogía de la Compañía de Jesús ante los retos del mundo actual. Padres y Maestros, 380, 71-76. DOl: https://doi.org/10.14422/pym.i380.y2019.012 ha hecho anteriormente. El P. General Io explica claramente en su misma carta: "El mejor homenaje que podemos ofrecer a nuestra larga tradición educativa es poder explorar nuevos modelos, modos creativos e imaginativos, para ofrecer nuestra visión espiritual y experiencia educativa a nuestros estudiantes y familias. Por lo tanto, el nombre del documento refleja bien su propósito: renovar nuestra tradición viva en la educación, como un ejercicio continuo de discernimiento".

Una tradición viva busca ser un instrumento que mantenga a los colegios en una actitud permanente de discernimiento y de apertura a la realidad. Por ello el documento mismo es "un discernimiento inacabado, un texto vivo que invita a los educadores de nuestras escuelas a enriquecerlo con sus reflexiones, experiencias y contribuciones. En este sentido, este es un documento abierto que modela el discernimiento que pretende inspirar, y quiere proporcionar pautas para continuar la educación de hombres y mujeres para y con los demás en el contexto de la excelencia humana, que distingue nuestra tradición educativa". (Carta del P. General Sosa anunciando el documento, 5 de noviembre de 2019). El prólogo del documento lo explica claramente: "No queremos un documento estático sino un texto que inspire, mueva y anime a nuestros docentes, líderes y comunidades educativas a comprometerse de manera proactiva con nuestro contexto, nuestro mundo, nuestros desafíos y nuestras oportunidades" •

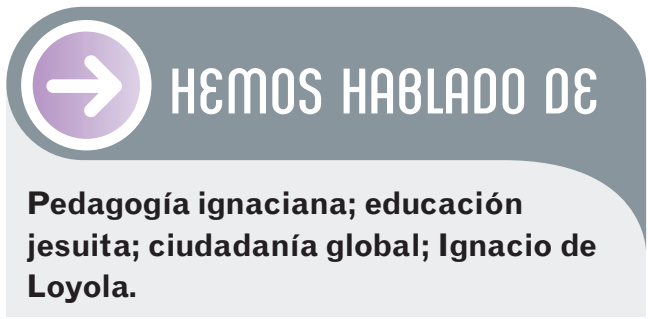

Este artículo fue solicitado por PADRES Y MAESTROS en septiembre de 2019, revisado y aceptado en febrero de 2020. 